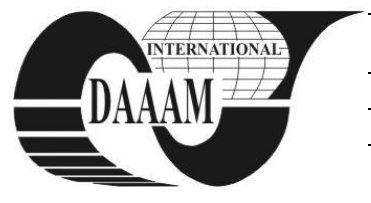

Annals of DAAAM for 2011 \& Proceedings of the 22nd International DAAAM Symposium, Volume 22, No. 1, ISSN 1726-9679 ISBN 978-3-901509-83-4, Editor B. Katalinic, Published by DAAAM International, Vienna, Austria, EU, 2011 Make Harmony between Technology and Nature, and Your Mind will Fly Free as a Bird Annals \& Proceedings of DAAAM International 2011

\title{
DYNAMIC IDENTIFICATION OF CIRCUIT WITH LINEAR OPTOCOUPLER IL300
}

\author{
OTAHAL, J[iri] \& HRUSKA, F[rantisek]
}

\begin{abstract}
This paper describes finding of dynamic behavior of a circuit with linear optocoupler IL300. There are described methods, equations and simulations of the circuit with linear optocoupler IL300. Trains from real measuremens are compared with the identified and simulated trains. Measurement equipment was connected to computer and the VEE PRO 9.0 software was used for measurment.

The research work was performed with the financial support of grant reg. No IGA/32/FAI/11/D and by the European Regional Development Fund under the project CEBIA-Tech No.CZ.1.05/2.1.00/03.0089.

Key words: embedded systems, galvanic separation, linear optocoupler, Strejc identification method
\end{abstract}

\section{INTRODUCTION}

All digital and analog inputs of embedded system must be protected against external overvoltage surges that can destroy the embedded system. In many applications it is necessary to protect devices or components, or separate differences in ground potential and therefore protect the parts of electric circuit. Optocouplers are the most used devices to separate circuits and their diferent potentials. If a time variant signal is used it is necessary to know the dynamic characteristic of the optocoupler considering this added circuit to signal path circuit which changes this signal.

\section{THE LINEAR OPTOCOUPLER HISTORY}

S. Waaben in 1975 first announced creation of an optocoupler with one LED diode and two photodiodes in the same optical space. The first photodiode is used as output and the second photodiode is used in the input circuit feedback. It was the first time a temperature stability linear optocoupler was officially published. There are some companies in todays market that produce optocouplers based on the same principle and function.

Problem of the protection of analog signals is in the maintainance of the linearity and stability of the surge when time-varying signals are used.

\section{USED CIRCUIT}

The test module was created and the mentioned circuit was placed on it. For the circuit with the linear optocoupler IL300 connection a different schematic was used compared to the datasheet of IL300. Oscillation on the same amplitude and frequency was also present when the DC invariable input was used. The oscillation frequency was $178.6 \mathrm{kHz}$ and the amplitude was $1.49 \mathrm{~V}$. When $1 \mathrm{nF}$ capacitor was added to the input operational amplifier negative feedback, the oscillation was removed.

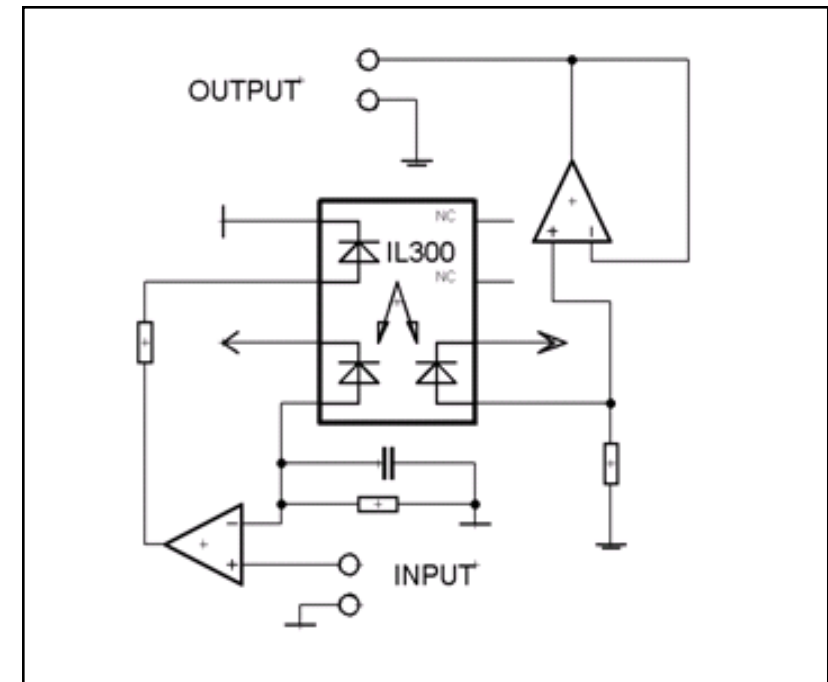

Fig. 1. The circuit schematic used with IL300 linear optocoupler

\section{DYNAMIC INPUT I OUTPUT CHARACTERISTICS MEASUREMENT USED EQUIPMENT}

- Agilent 33220A Function / Arbitrary Waveform Generator, $20 \mathrm{MHz}$ as source of signal

- Agilent DSO6104A Oscilloscope: $1 \mathrm{GHz}, 4$ channels

- 3x N2862A Passive Probe, 10:1, $150 \mathrm{MHz}, 1.2 \mathrm{~m}$

- Probes were compared and set to the same gain.

\section{STREJC IDENTIFICATION METHOD}

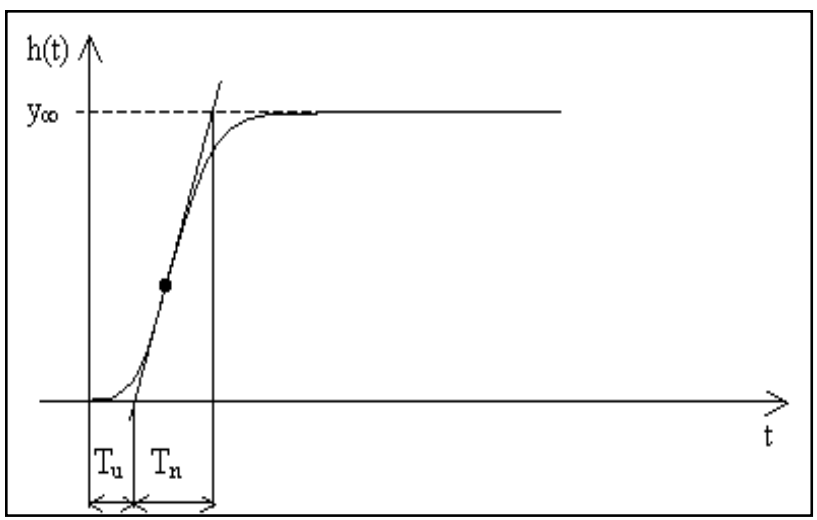

Fig. 2. The aperiodic step response with a rise time and a delay time displayed

If the step response of the controlled system has an aperiodic train, we can approach it by a second order 
proportional plant with a different time constants or by $\mathrm{a}^{\text {th }}$ order proportional plant with same-time constants. The choice of the type of the model's plant is dependent on a parameter $\tau$, which is computed as:

$$
\tau=\frac{T_{u}}{T_{n}}
$$

where: $T_{u}$ - delay time, $T_{n}-$ rise time

If the parameter $\tau$ is smaller than 0.1 , the proportional plant with a different time constants is chosen, otherwise the proportional plant with same-time constants is chosen.

$$
\begin{array}{cc}
\Rightarrow \text { Will be } & \multicolumn{1}{c}{\begin{array}{c}
K \\
\tau<0.1 \text { approximated in form }
\end{array}} \\
\tau \geq 0.1 \quad \begin{array}{c}
\Rightarrow \text { Will be } \\
\text { approximated in form }
\end{array} & G(s)=\frac{K}{(T s+1)^{2}}
\end{array}
$$

\section{CIRCUIT WITH IL300 IDENTIFICATION}

As is evident on the figure 3 output from the circuit with I300 has an aperiodic train, therefore the Strejc identification method could be used. In this case, after the step change of the signal, the signal follows an insensitivity zone which has duration of $2.35 \mu \mathrm{s}$. It stands to reason that the insensitivity zone does not depend on the input frequency.

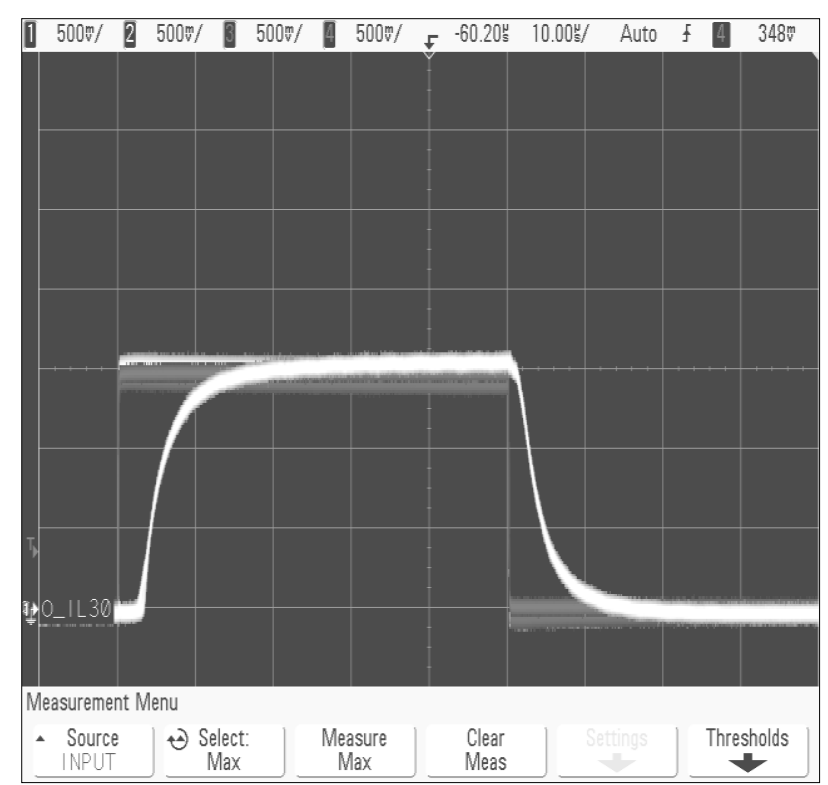

Fig. 3. Real input and output train of singnals

As mentioned before, the Strejc identification method was used for identification. Since $\tau<0.1$, thereby the transfer function with different time constants was chosen. Resulting transfer function of the circuit with IL300 is in the form

$$
G(s)=\frac{1}{(0.8698 s+1) \cdot(1.615 s+1)}
$$

The next step was a simulation of the system using Matlab Simulink software.

Simulation in Matlab Simulink was done and hereinbefore the simulation output curve strictly imitates the output signal from the circuit with the IL300 as can be seen in Fig. 5.

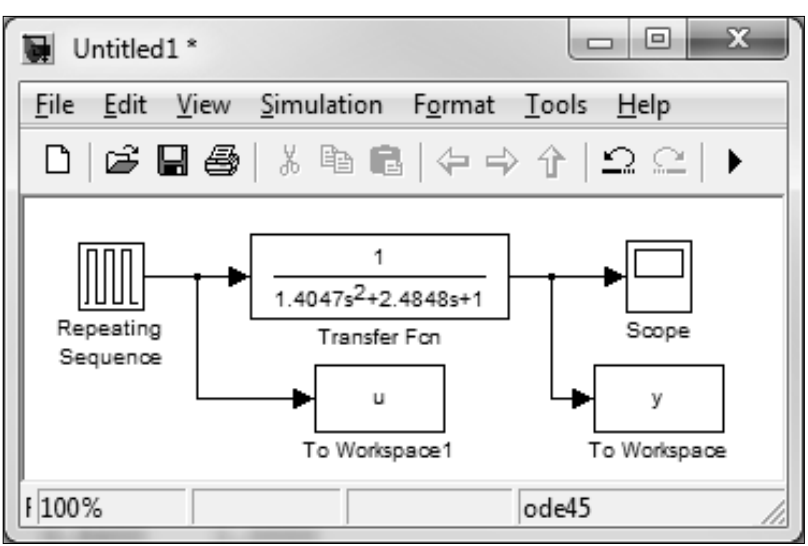

Fig. 4. The schematic in Matlab Simuling

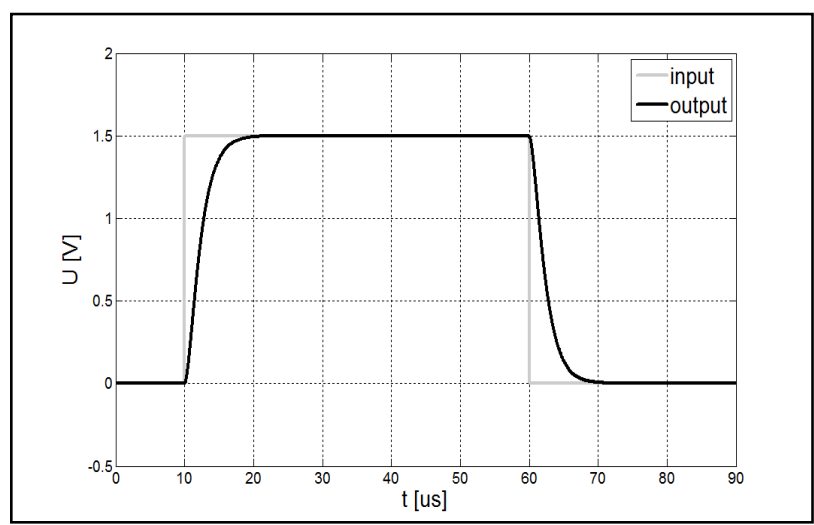

Fig. 5. The simulation in the Matlab Simuling

\section{CONCLUSION}

Principles for finding the dynamic characteristics of protections of input and output signals were described, demonstrated and the behavior and mathematical description of a circuit with IL300 was found.

Another part of the work has been a mathematical description of the behavior of other protections of inputs and outputs; and to model these circuit behaviors in Matlab Simulink.

\section{ACKNOWLEDGEMENTS}

This paper is supported by the Internal Grant Agency at Tomas Bata University in Zlin, project No. IGA/32/FAI/11/D and by the European Regional Development Fund under the project CEBIA-Tech No.CZ.1.05/2.1.00/03.0089.

\section{REFERENCES}

Balátě, J. (2003). Automatické řizení.: BEN, ISBN 8073000202, Praha, Czech Republic

Corriou, J. (2004). Process control: Theory and applications. Springler, ISBN 1852337761, USA

Otáhal, J, et al. (2011). Protections of embedded systems inputs. In OTÁHAL, Jiří. Proceedings of 13th WSEAS International Conference on AUTOMATIC CONTROL, MODELLING \& SIMULATION (ACMOS '11). Otáhal J. (Ed.), pp. 407-411.

Svačina, J. (2000). Zdroje rušivých signálů a vazební mechanismy jejich přenosu [online], Available from: WWW: <http://www.elektrorevue.cz/clanky/00031/index.ht ml\#kapI $>$.Accessed:2009-20-04

Tumanski, S. (2006). Principles of electrical measurement. Taylor\&Francis Group, ISBN 0-7503-1038-3

STMicroelectronics. (1998). Datasheet IL300 